\title{
The Study of in vitro and in vivo Effects of Concurrent Administration of Paracetamol and Zinc on the Antibacterial Activity of Ciprofloxacin
}

\author{
Muhammad Rezwanul Ahsan', Md. Zakir Sultan², Mohammad Abdullahil Baki ${ }^{1}$, \\ Md. Aknur Rahman ${ }^{1}$, Md. Aslam Hossain ${ }^{1}$, Md. Amjad Hossain ${ }^{1}$ \\ and Md. Shah Amran ${ }^{1}$ \\ ${ }^{1}$ Department of Pharmaceutical Chemistry, Faculty of Pharmacy, University of Dhaka, Dhaka-1000, \\ Bangladesh \\ ${ }^{2}$ Drug Research Laboratory, Centre for Advanced Research in Sciences, University of Dhaka, Dhaka-1000, \\ Bangladesh
}

\begin{abstract}
Concurrent administration of more than one drug is a common practice in medical science and in such case one drug may affect the pharmacology of another drug. Ciprofloxacin is a commonly used antibiotic in Bangladesh and frequently prescribed with paracetamol and zinc salt for concomitant use in patients suffering from infections. Therefore, the interaction of ciprofloxacin with paracetamol and zinc salt was studied in vitro at $\mathrm{pH} 1.2$, 6.8 and 7.4 which are related to gastric, intestinal juices and blood environment, respectively. In vitro evaluation of ciprofloxacin complexes with paracetamol and zinc was carried on several gram positive and gram negative microorganisms by disc diffusion method. The in vivo effect of the complexes was assessed by determining the plasma concentration in mice by spectroscopic method. It was observed that in the in vitro study paracetamol and zinc has insignificant effect on the antibacterial activity of ciprofloxacin although zinc itself showed some antibacterial activity; and in the in vivo study it was found that zinc sulphate reduced the bioavailability of ciprofloxacin $\mathrm{HCl}$.
\end{abstract}

Key words: Ciprofloxacin, Paracetamol, Zinc, Interaction, Concurrent administration, Disc diffusion, In vitro and In vivo

\section{INTRODUCTION}

A drug interaction can be defined as the modification of the effects of one drug by the other drug. The interaction can modify the drugs by forming chemical complex, nullify the action, increase the effect, decrease the effect, induce or inhibit the hepatic metabolism and elimination rate, create an environment (by changing the $\mathrm{pH}$ of the stomach or urine, by increasing or decreasing the sensitivity to other drugs) where the other drug failed to exert its effects. The net result may be enhanced or diminished effects of one or both the drugs. ${ }^{1}$ A drug

Correspondence to: Md. Shah Amran

Tel.: 880-2- 9661900-73, Extn. - 8130, 8137;

Fax: 880-2-8615583; E-mail: amdshah_69@yahoo.com

Dhaka Univ. J. Pharm. Sci. 10(2): 137-142, 2011 (December) interaction may be pharmacokinetic or pharmacodymamic in nature. Pharmacokinetic interactions influence the deposition of a drug in the body and involve the effects of one drug on the absorption, distribution, metabolism and excretion of another. Due to large inter and intra patient variability in drug disposition, pharmacokinetic interaction seldom produces serious clinical consequences. Pharmacokinetic interactions are frequently associated with changes in plasma drug concentration and when feasible, observing the clinical status of the patients as well as monitoring serum drug levels may provide useful information about potential interactions. Pharmacodynamic interactions are related to the pharmacologic activity of the interacting drugs. These are more frequent mechanism of pharmacodynamic interactions includes synergism, antagonism, altered cellular 
transport and effects on receptor sites. When a drug is administered orally, it first must be dissolved in GI fluids before transport can take place across a membrane into the systemic circulation. The drug is then distributed to various parts of the body where it may be stored, metabolized, exert a pharmacological action, or be excreted. Thus a drug may come in close contact with food staffs and different body components or with another drug(s) that has been administered simultaneously, just prior to or just after itself and it may form complex with such drugs. This may be harmful or harmless. Adverse drug interactions can cause a loss in therapeutic activity, toxicity or unexpected increase in pharmacological activity of a drug arising from alteration of absorption, bioavailability and other biochemical process. Therefore, it should be known the possible interaction of a new drug when it goes to be used clinically. The study of drug interactions occupies an important place in the field of drug research, especially drug design and drug development. Such study is compulsory for the newer drugs. ${ }^{2}$

In continuation of our research on the assessment of the interaction of very commonly used antibiotic with paracetamol and zinc, we already reported the interaction of ciprofloxacin with paracetamol and zinc sulfate. In this paper we report the in vitro and in vivo effects of concurrent administration of paracetamol and zinc on the antibacterial activity of ciprofloxacin. ${ }^{9}$

\section{MATERIALS AND METHODS}

Drugs and Chemicals. The working standards of ciprofloxacin and paracetamol were the kind gift from Healthcare Pharmaceuticals, Dhaka, Bangladesh. Hydrochloric acid (37\%), zinc sulfate, sodium chloride, potassium dihydrogen orthophosphate, orthophosphoric acid, potassium hydroxide, sodium hydroxide, potassium bromide, heparin, were purchased from local market. Nutrient agar medium was purchased from DIFCO.

Preparation of buffer solutions ${ }^{3,4} \cdot \mathrm{pH}$ 1.2. To prepare 1 liter of $\mathrm{pH} 1.2$ buffer, $2 \mathrm{~g}$ of sodium chloride and $0.1 \mathrm{M} \mathrm{HCl}$ were taken in a $1000 \mathrm{~mL}$ volumetric flask and dissolved in $600 \mathrm{~mL}$ of distilled water. Finally the volume was made up to the mark with distilled water. The $\mathrm{pH}$ was adjusted to 1.2 by using $\mathrm{HCl}$.

pH 6.8. To prepare 1 liter of $\mathrm{pH} 6.8$ phosphate buffer, $6.8 \mathrm{~g}$ of monobasic potassium phosphate and $77 \mathrm{~mL}$ of $0.2 \mathrm{M}$ sodium hydroxide were taken in a $1000 \mathrm{~mL}$ volumetric flask and dissolved in $600 \mathrm{~mL}$ of distilled water. Finally the volume was made up to the mark with distilled water. The $\mathrm{pH}$ was adjusted to 6.8 by using $\mathrm{HCl}$ or $\mathrm{NaOH}$ as needed.

pH 7.4. To prepare 1 liter of $\mathrm{pH} 7.4$ phosphate buffer, $65.4 \mathrm{~mL}$ of $0.02 \mathrm{M}$ monobasic potassium phosphate and $289.7 \mathrm{~mL}$ of $0.001 \mathrm{M}$ dibasic sodium phosphate were taken in a $1000 \mathrm{~mL}$ volumetric flask and dissolved in $600 \mathrm{~mL}$ of distilled water. Finally the volume was made up to the mark with distilled water. The $\mathrm{pH}$ was adjusted to 7.4 by using dilute phosphoric acid.

Test microorganisms. Bacterial strains Bacillus cereus, Bacillus subtilis, Staphylococcus aureus, Escherichia coli, Pseudomonas aeruginosa and Shigella boydii were collected as pure cultures the from the Biomedical Research Centre, Faculty of Pharmacy, University of Dhaka. The tests were also performed in this Centre.

Test animals. Nine healthy mice weighing about $200 \pm 25$ g used as the experimental animals for in vivo experiments were purchased from the International Centre for Diarrheal Disease Research, Bangladesh (ICDDRB).

Preparation of disc. Discs were prepared by using special punching machine with a diameter of 8 $\mathrm{mm}$ and then these discs were placed in a screw-cap vial and autoclaved for use.

Preparation of samples. To prepare 1:1 mixture, $1.0 \mathrm{~g}$ of each test sample was dissolved in $100 \mathrm{~mL}$ of solvent (buffer solution of $\mathrm{pH}$ 1.2, 6.8 and 7.4) to obtain the desired concentrations. To prepare 1:10 ciprofloxacin and $\mathrm{Zn}$ mixture, $1.0 \mathrm{~g}$ ciprofloxacin and $10.0 \mathrm{~g} \mathrm{Zn}$ was dissolved in $100 \mathrm{~mL}$ buffer solution of $\mathrm{pH}$ 1.2. The sample discs were impregnated with the samples as mentioned in the table-1with the help of micropipette (Table 1) 
Table 1. Preparation of samples and discs for microbial experiment

\begin{tabular}{llcc}
\hline \multicolumn{1}{c}{ Name of Samples } & Conc. of Stock $(\mu \mathrm{g} / \mathrm{mL})$ & $\mu \mathrm{L}$ added per disc & Conc. $(\mu \mathrm{g} /$ disc $)$ \\
\hline Ciprofloxacin & 10000 & 5 and 10 & 50 and 100 \\
Paracetamol & 10000 & 5 and 10 & 50 and 100 \\
Zinc & 10000 & 5 and 10 & 50 and 100 \\
Zinc & 1000 & 50 and 100 & 500 and 1000 \\
Ciprofloxacin+ Paracetamol (1:1) & 10000 & 5 and 10 & $50+50$ and $100+100$ \\
Ciprofloxacin+ Zinc (1:1) & 10000 & 5 and 10 & $50+50$ and $100+100$ \\
Ciprofloxacin+ Zinc (1:10) & 1000 & 5,50 and 10,100 & $50+500$ and $100+1000$ \\
\hline
\end{tabular}

Assay of antimicrobial activity ${ }^{10-12}$. A paperdisc diffusion method was used to measure antimicrobial activities. Sterilized, autoclaved and inoculated nutrient agar media was poured into Petri dishes (diameter of $100 \mathrm{~mm}$ ) giving a depth of 3-4 $\mathrm{mm}$. Paper discs (diameter of $8 \mathrm{~mm}$ ) impregnated with specified concentrations of the test samples were placed on the surface of the agar plates. The plates were incubated at $37{ }^{\circ} \mathrm{C}$ for $24 \mathrm{~h}$. Antimicrobial activities were measured as diameter of the zone of inhibition of the growth of microbes. Kanamycin (30 $\mu \mathrm{g} / \mathrm{disc})$ was used as the reference standard for positive control. Blank disc were also used to ensure that the residual solvent (left over the discs even after air-drying) is free from antimicrobial activities.

Determination of plasma concentration of ciprofloxacin and its complexes in mice ${ }^{13,14}$. The experiment was done to determine the effect of zinc sulphate on the bioavailability of ciprofloxacin in mice. UV spectroscopic method was used for the determination. The experimental animals were kept 7 days with normal diet and in the normal cycle of light and dark for $24 \mathrm{~h}$. Eight mice were divided into two groups having 4 animals in each of the group and marked as 1 and 2. One mouse was kept as control. All the mice were fasted overnight before the drug administration. $\quad 2.0 \mathrm{mg}$ ciprofloxacin was administered in group-I animals by orogastric tube and another group was received 1:1 mixture of ciprofloxacin with zinc. After 2 hours from drug administration these rats were sacrificed and blood samples were collected in a heparinized screw cap test tube. All blood samples were protected from light and centrifuged immediately at $3000 \mathrm{rpm}$ for 10 minutes and plasma samples were separated into vials and preserved at $-18{ }^{\circ} \mathrm{C}$ until measuring the absorbance.

Preparation of calibration curve. To prepare a calibration curve, $1 \mathrm{~mL}$ of $20 \mu \mathrm{g} / \mathrm{ml}$ ciprofloxacin solution was added into $1 \mathrm{ml}$ of plasma and diluted with plasma to obtain the concentration as $0,25,50$, $75,100,125,150 \mathrm{ng} / \mathrm{ml}$, respectively. The absorbance of each of the solutions was taken three times. Finally, average absorbance were plotted against concentrations and a calibration curve was obtained.

Data analysis and statistics. Statistical analysis was based on the guidelines for statistics and modified for the study of in vitro and in vivo studies ${ }^{15}$. The results were expressed as mean \pm SD . Differences in mean values between experimental groups (in vitro and in vivo) were analysis by one way analysis of variance, followed by Dunnett's multiple comparison tests where applicable. A $p$ value less than 0.01 was defined to be significant.

\section{RESULTS AND DISCUSSION}

The results of antimicrobial properties of ciprofloxacin and its $(1: 1)$ mixture with paracetamol and zinc at pH 1.2, 6.8 and 7.4 showed almost similar activities in comparison to ciprofloxacin against the tested microorganisms (Tables 2 - 4). The results also showed that zinc itself has some antimicrobial properties at higher doses (500 and $1000 \mu \mathrm{g} / \mathrm{disc}$ ). The 1:10 mixture of ciprofloxacin with $\mathrm{Zn}$ showed a little antimicrobial activity against $S$. aureus (Table $5)$. 
Table 2. Antimicrobial activity of ciprofloxacin and its 1:1 mixture at $\mathbf{p H} 1.2(\mathrm{n}=5, \mathrm{C}=\mathrm{Ciprofloxacin}, \mathrm{P}=\mathrm{Paracetamol}, \mathrm{Z}=\mathrm{Zinc}$, Kan=Kanamycin)

\begin{tabular}{|c|c|c|c|c|c|c|c|c|c|c|c|}
\hline \multirow{3}{*}{$\begin{array}{l}\text { Test micro- } \\
\text { organisms }\end{array}$} & \multicolumn{11}{|c|}{ Diameter of zone of inhibition (mm) } \\
\hline & \multicolumn{2}{|c|}{ C } & \multicolumn{2}{|c|}{$\mathbf{P}$} & \multicolumn{2}{|c|}{$\mathbf{Z}$} & \multicolumn{2}{|c|}{$\mathrm{C}+\mathrm{P}(1: 1)$} & \multicolumn{2}{|c|}{$C+Z(1: 1)$} & \multirow{2}{*}{$\begin{array}{c}\text { Kan } \\
35 \mu g\end{array}$} \\
\hline & $50 \mu \mathrm{g}$ & $100 \mu \mathrm{g}$ & $50 \mu g$ & $100 \mu \mathrm{g}$ & $50 \mu \mathrm{g}$ & $100 \mu \mathrm{g}$ & $50+50 \mu g$ & $100+100 \mu g$ & $50+50 \mu \mathrm{g}$ & $100+100 \mu g$ & \\
\hline \multicolumn{12}{|c|}{ Gram positive bacteria } \\
\hline B. cereus & $50 \pm 0.5$ & $52 \pm 0.5$ & Nil & Nil & Nil & Nil & $51 \pm 1$ & $51 \pm 0.5$ & $54 \pm 0.5$ & $54 \pm 0.5$ & $34 \pm 0.5$ \\
\hline B. subtilis & $51 \pm 1$ & $54 \pm 0.5$ & Nil & Nil & Nil & Nil & $51 \pm 1.3$ & $55 \pm 1$ & $52 \pm 0.5$ & $52 \pm 0.5$ & $35 \pm 0.5$ \\
\hline S. aureus & $53 \pm 0.5$ & $55 \pm 0.5$ & Nil & Nil & Nil & Nil & $52 \pm 1$ & $54 \pm 1.3$ & $53 \pm 1$ & $52 \pm 0.5$ & $35 \pm 0.5$ \\
\hline \multicolumn{12}{|c|}{ Gram negative bacteria } \\
\hline E. coli & $50 \pm 0.5$ & $55 \pm 0.5$ & Nil & Nil & Nil & Nil & $52 \pm 0.5$ & $54 \pm 0.5$ & $52 \pm 0.5$ & $54 \pm 0.5$ & $35 \pm 0.5$ \\
\hline Ps. aeruginosa & $52 \pm 1$ & $53 \pm 1$ & Nil & Nil & Nil & Nil & $53 \pm 1$ & $56 \pm 1$ & $54 \pm 0.5$ & $55 \pm 0.5$ & $34 \pm 0.5$ \\
\hline Sh. boydii & $50 \pm 0.5$ & $55 \pm 1$ & Nil & Nil & Nil & Nil & $53 \pm 0.5$ & $55 \pm 0.5$ & $52 \pm 1$ & $54 \pm 1$ & $35 \pm 0.5$ \\
\hline
\end{tabular}

Table 3. Antimicrobial activity of ciprofloxacin and its mixture $1: 1$ at $\mathrm{pH} 6.8(\mathrm{n}=5, \mathrm{C}=\mathrm{Ciprofloxacin}, \mathrm{P}=\mathrm{Paracetamol}, \mathrm{Z}=\mathrm{Zinc}$, Kan=Kanamycin)

\begin{tabular}{|c|c|c|c|c|c|c|c|c|c|c|c|}
\hline \multirow[b]{3}{*}{$\begin{array}{l}\text { Test } \\
\text { microorganisms }\end{array}$} & \multicolumn{11}{|c|}{ Diameter of zone of inhibition (mm) } \\
\hline & \multicolumn{2}{|c|}{$\mathbf{C}$} & \multicolumn{2}{|c|}{$\mathbf{P}$} & \multicolumn{2}{|c|}{$\mathbf{Z}$} & \multicolumn{2}{|c|}{$C+P(1: 1)$} & \multicolumn{2}{|c|}{$C+Z(1: 1)$} & \multirow{2}{*}{$\begin{array}{l}\text { Kan } \\
35 \mu \mathrm{g}\end{array}$} \\
\hline & $50 \mu \mathrm{g}$ & $100 \mu \mathrm{g}$ & $50 \mu g$ & $100 \mu \mathrm{g}$ & $50 \mu \mathrm{g}$ & $100 \mu g$ & $\begin{array}{c}50+ \\
50 \mu \mathrm{g}\end{array}$ & $\begin{array}{c}100+ \\
100 \mu g\end{array}$ & $\begin{array}{c}50+ \\
50 \mu g\end{array}$ & $\begin{array}{c}100+ \\
100 \mu \mathrm{g}\end{array}$ & \\
\hline \multicolumn{12}{|c|}{ Gram positive bacteria } \\
\hline B. cereus & $45 \pm 0.5$ & $50 \pm 1$ & Nil & Nil & Nil & Nil & $46 \pm 0.5$ & $51 \pm 0.5$ & $45 \pm 0.5$ & $49 \pm 0.5$ & $37 \pm 0.5$ \\
\hline B. subtilis & $48 \pm 1$ & $52 \pm 0.5$ & Nil & Nil & Nil & Nil & $51 \pm 0.5$ & $50 \pm 1$ & $50 \pm 1$ & $50 \pm 0.5$ & $37 \pm 0.5$ \\
\hline S. aureus & $47 \pm 0.5$ & $50 \pm 0.5$ & Nil & Nil & Nil & Nil & $48 \pm 0.5$ & $50 \pm 0.5$ & $50 \pm 1$ & $52 \pm 0.5$ & $37 \pm 0.5$ \\
\hline \multicolumn{12}{|c|}{ Gram negative bacteria } \\
\hline E. coli & $50 \pm 1$ & $52 \pm 0.5$ & Nil & Nil & Nil & Nil & $48 \pm 0.5$ & $50 \pm 0.5$ & $49 \pm 0.5$ & $50 \pm 0.5$ & $37 \pm 0.5$ \\
\hline Ps. aeruginosa & $50 \pm 0.5$ & $55 \pm 0.5$ & Nil & Nil & Nil & Nil & $48 \pm 0.5$ & $54 \pm 0.5$ & $50 \pm 1$ & $54 \pm 0.5$ & $37 \pm 0.5$ \\
\hline Sh. boydii & $48 \pm 0.5$ & $52 \pm 0.5$ & Nil & Nil & Nil & Nil & $47 \pm 0.5$ & $48 \pm 0.5$ & $50 \pm 1$ & $53 \pm 0.5$ & $37 \pm 0.5$ \\
\hline
\end{tabular}

Table 4. Antimicrobial activity of ciprofloxacin and its $1: 1$ mixture at $\mathrm{pH} 7.4$ (n=5, C=Ciprofloxacin, $\mathrm{P}=$ Paracetamol, $\mathrm{Z}=\mathrm{Zinc}$, Kan=Kanamycin)

\begin{tabular}{|c|c|c|c|c|c|c|c|c|c|c|c|}
\hline \multirow{3}{*}{$\begin{array}{l}\text { Test } \\
\text { microorganisms }\end{array}$} & \multicolumn{11}{|c|}{ Diameter of zone of inhibition (mm) } \\
\hline & \multicolumn{2}{|c|}{ C } & \multicolumn{2}{|c|}{$\mathbf{P}$} & \multicolumn{2}{|c|}{$\mathbf{Z}$} & \multicolumn{2}{|c|}{$\mathrm{C}+\mathrm{P}(1: 1)$} & \multicolumn{2}{|c|}{$C+Z \quad(1: 1)$} & \multirow{2}{*}{$\begin{array}{c}\text { Kan } \\
35 \\
\mu \mathrm{g} \\
\end{array}$} \\
\hline & $50 \mu g$ & $100 \mu \mathrm{g}$ & $50 \mu g$ & $100 \mu g$ & $50 \mu \mathrm{g}$ & $100 \mu g$ & $\begin{array}{c}50+ \\
50 \mu g \\
\end{array}$ & $\begin{array}{c}100+ \\
100 \mu g \\
\end{array}$ & $\begin{array}{c}50+ \\
50 \mu g \\
\end{array}$ & $\begin{array}{c}100+ \\
100 \mu \mathrm{g}\end{array}$ & \\
\hline \multicolumn{12}{|c|}{ Gram positive bacteria } \\
\hline B. cereus & $50 \pm 0.5$ & $52 \pm 0.5$ & Nil & Nil & Nil & Nil & $50 \pm 0.5$ & $50 \pm 0.5$ & $48 \pm 0.5$ & $50 \pm 0.5$ & $35 \pm 0.5$ \\
\hline B. subtilis & $54 \pm 1$ & $56 \pm 1.3$ & Nil & Nil & Nil & Nil & $55 \pm 1$ & $56 \pm 1.3$ & $52 \pm 0.5$ & $52 \pm 0.5$ & $35 \pm 0.5$ \\
\hline S. aureus & $52 \pm 0.5$ & $54 \pm 0.5$ & Nil & Nil & Nil & Nil & $54 \pm 0.5$ & $56 \pm 0.5$ & $50 \pm 0.5$ & $52 \pm 0.5$ & $35 \pm 0.5$ \\
\hline \multicolumn{12}{|c|}{ Gram negative bacteria } \\
\hline E. coli & $50 \pm 0.5$ & $54 \pm 0.5$ & Nil & Nil & Nil & Nil & $52 \pm 0.5$ & $56 \pm 0.5$ & $52 \pm 0.5$ & $56 \pm 0.5$ & $35 \pm 0.5$ \\
\hline Ps. aeruginosa & $52 \pm 1$ & $54 \pm 1.3$ & Nil & Nil & $\mathrm{Nil}$ & Nil & $54 \pm 1$ & $56 \pm 1.3$ & $50 \pm 0.5$ & $54 \pm 0.5$ & $35 \pm 0.5$ \\
\hline Sh. boydii & $52 \pm 0.5$ & $55 \pm 0.5$ & Nil & Nil & Nil & Nil & $54 \pm 0.5$ & $56 \pm 0.5$ & $51 \pm 0.5$ & $54 \pm 0.5$ & $35 \pm 0.5$ \\
\hline
\end{tabular}

Table 5. Antimicrobial activity of ciprofloxacin and zinc 1:10 mixture at pH 1.2 (n=5, C=Ciprofloxacin, Z=Zinc, Kan=Kanamycin)

\begin{tabular}{lccccc}
\hline & \multicolumn{5}{c}{ Diameter of zone of inhibition (mm) } \\
\cline { 2 - 6 } Test microorganisms & \multicolumn{3}{c}{$\mathbf{Z}$} & \multicolumn{4}{c}{ C+Z (1:10) } & Kan \\
\cline { 2 - 6 } & $500 \mu \mathrm{g}$ & $1000 \mu \mathrm{g}$ & $50+500 \mu \mathrm{g}$ & $100+1000 \mu \mathrm{g}$ & $35 \mu \mathrm{g}$ \\
\hline Gram positive bacteria & $18 \pm 1.3$ & $20 \pm 1$ & $51 \pm 1$ & $54 \pm 1$ & $34 \pm 0.5$ \\
B. cereus & $18 \pm 0.5$ & $20 \pm 0.5$ & $52 \pm 0.5$ & $55 \pm 0.5$ & $35 \pm 0.5$ \\
B. subtilis & $18 \pm 1$ & $20 \pm 1.3$ & $56 \pm 1.3$ & $64 \pm 1.3$ & $35 \pm 0.5$ \\
S. aureus & $18 \pm 0.5$ & $22 \pm 0.5$ & $51 \pm 0.5$ & $52 \pm 0.5$ & $36 \pm 0.5$ \\
Gram negative bacteria & $18 \pm 1$ & $20 \pm 1$ & $52 \pm 1$ & $55 \pm 1$ & $34 \pm 0.5$ \\
E. coli & $18 \pm 0.5$ & $22 \pm 0.5$ & $50 \pm 0.5$ & $55 \pm 0.5$ & $31 \pm 0.5$ \\
Ps. aeruginosa & & & & & \\
Sh. boydii & & & & & \\
\end{tabular}

When absorbance (y) was plotted against concentration (c), a good correlation coefficient was obtained in concentration range of $0,25,50,75$, $100,125,150 \mathrm{ng} / \mathrm{mL}$. For the equation of calibration 
curve correlation co-efficient $\left(\mathrm{r}^{2}\right)$ was obtained as

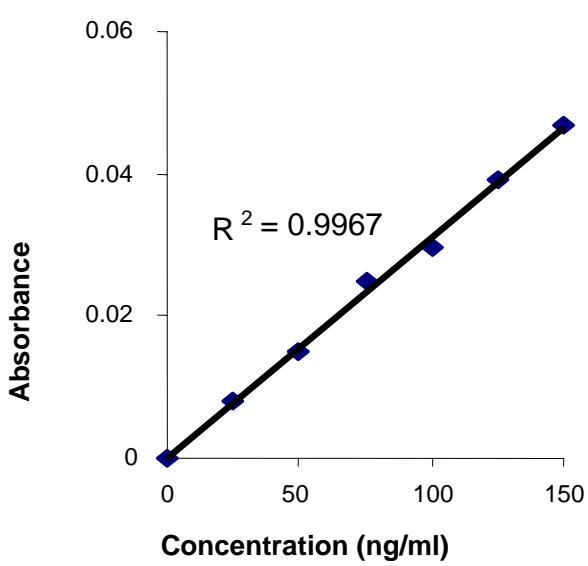

0.996 which indicated good linearity of the newly developed method (Figure 1).

In vivo bioavailability study showed that when (1:1) mixtures of ciprofloxacin with zinc were administered in mice then there was a significant diminution of bioavailability in comparison to ciprofloxacin. The plasma concentration of ciprofloxacin was found as $86.26 \mathrm{ng} / \mathrm{ml}$ whereas it was $59.1 \mathrm{ng} / \mathrm{ml}$ when administered with zinc sulphate (Table 6). These results are comparable with other investigators ${ }^{5-8}$.

Figure 1. Absorbance versus concentration curve for ciprofloxacin

Table 6. Average plasma concentration of ciprofloxacin after single oral administration and after oral administration of ciprofloxacin and Zinc 1:1 mixture.

\begin{tabular}{ccc|cr}
\hline Time (hour) & Absorbance & Conc.of Cipro (ng/ml) & Absorbance & Conc. of Cipro + Zinc (ng/ml) \\
\hline 2 & 0.0267 & 90.5 & 0.0201 & 68.1 \\
2 & 0.0301 & 102.03 & 0.0159 & 53.8 \\
2 & 0.0195 & 66.10 & 0.0166 & 56.2 \\
2 & 0.0255 & 86.4 & 0.0172 & 58.3 \\
& & Av conc. 86.26 & & Av conc. 59.1 \\
\hline
\end{tabular}

\section{CONCLUSION}

Multiple drug therapy is a common practice in modern medical science, especially for hospitalized patients. There may be chances of interactions, which are unexpected. Therefore this study on interaction of ciprofloxacin $\mathrm{HCl}$ with zinc and paracetamol is important with respect to biopharmaceutics, pharmacology and drug development. The in vitro antimicrobial studies showed that 1:1 mixtures of ciprofloxacin with paracetamol and zinc have almost same antimicrobial activity against three gram positive and three gram negative bacteria in comparison to ciprofloxacin at different $\mathrm{pH}(1.2,6.8$, and 7.4). The antimicrobial activity against $S$. aureus was much improved at $\mathrm{pH} 1.2$ when 1:10 mixture ciprofloxacin and $\mathrm{Zn}$ was applied. The in vivo study for determination of plasma concentration of ciprofloxacin $\mathrm{HCl}$ in rat by $\mathrm{UV}$ method showed that concurrent administration of zinc with ciprofloxacin have made noticeable changes in plasma concentration of ciprofloxacin $\mathrm{HCl}$.

\section{ACKNOWLEDGEMENT}

The authors would like to thank Professor Dr. Md. Abdur Rashid, the then Director of Biomedical research center for his kind permission to conduct the research work in the center. We also thank Mr. Haradhan Chandra Majumder for his assistance during the experiments.

\section{REFERENCES}

1. Cadwallader, D.E. 1985. Biopharmaceutics and drug interactions, 3rd edition, Raven press, New York, pp. 107143.

2. Gibaldi, M. 1977. Biopharmaceutics and clinical pharmacokinetics, $2^{\text {nd }}$ edition, Lea and Febiger, Philadelphia, pp. 1-13, 83-107.

3. Perrin D.D. and Boyd, D. 1974. Buffers for $\mathrm{pH}$ and metal ion control, Science papers back, p. 44-64.

4. Bates,B, 1964. Determination of $\mathrm{pH}$ - Theory and Practice, NewYork, Wily, pp. 50-67.

5. Anthony W. C., Justina W. and Karen H. B. 1988. Synergistic interactions of ciprofloxacin and extendedspectrum 1-lactams or aminoglycosides against multiply drug-resistant Pseudomonas maltophilia, Antimicrob. Agents Chemother. 32, 782-784. 
6. Moody J.A., Peterson L.R. and Gerding D.N. 1985. In vitro activity of ciprofloxacin combined with Azlocillin, Antimicrob. Agents Chemother. 28, 849-850.

7. Sege V.S., M. Rehavi and Rubinstein E. 1988. Quinolones, theophylline, and diclofenac interactions with the $y$ aminobutyric acid receptor, Antimicrob. Agents Chemother. 32, 1624-1626.

8. Amran, M.S., Bari, A.H.M.R. and Hossain, M.A. 2006. The in vitro and in vivo interactions of diltiazem with ibuprofen and naproxen in aqueous medium and rabbits, Dhaka Univ. $J$. Pharm. Sci. 5, 25-28.

9. Brunton Laurence, Blumenthal Donald, Buxton Iain and Parker Keith, 2007. Goodman and Gilman's Manual of Pharmacology and Therapeutics, McGraw-Hill. pp. 659, 722727.

10. Sultan, M.Z., Jeon, Y.-M.; Moon, S.-S. 2008. Labdane-type diterpenes active against acne from pine cones (Pinus densiflora). Planta Med. 74, 449-452,
11. Sultan, M.Z.; Lee, K.M. and Moon, S.-S. 2009. Antibacterial effect of naturally occurring unsaturated fatty acids from Prunus japonica against Propionibacterium acnes. Orient. Pharm. Exp. Med. 9, 90-96.

12. Cho, S.-C.. Sultan. M.Z. and Moon, S.-S. 2009. Anti-acne activities of pulsaquinone, hydropulsaquinone and structurally-related 1,4-quinone derivatives. Arch. Pharm. Res. 32, 489-494.

13. Mohiuddin, M., Azam, A.T.M.Z., Amran, M.S. and Hossain, M.A. 2009. In vivo effects of gliclazide and metformin on the plasma concentration of caffeine in healthy rats. Pak. J. Bio. Sci. 12, 734-737.

14. Bari, A.H.M.R., Azam, A.T.M.Z., Amran, M.S. and Hossain, M.A. 2000. In vivo effects of ibuprofen and naproxen on the plasma concentration of diltiazem in rabbits. Pak. J. Bio. Sci. 3, 555-557.

15. Wallstein, S., Zucker C.L. and Fleiss, J.L. 1980. Some statistical methods useful in circulation research. Circ. Res. 47, 1-9. 